\title{
THERMAL CONDUCTIVITY OF CONSTRUCTION MATERIALS BASED ON GYPSUM
}

\author{
Pavel Neuberger ${ }^{1}$, Aivars Aboltins ${ }^{2}$, Pavel Kic ${ }^{1}$ \\ ${ }^{1}$ Czech University of Life Sciences Prague, Czech Republic; \\ ${ }^{2}$ Latvia University of Life Sciences and Technologies, Latvia \\ neuberger@tf.czu.cz, aivars.aboltins@inbox.lv, kic@tf.czu.cz
}

\begin{abstract}
Reduction of energy consumption for buildings is important for new, but also for older buildings that require modernization and reconstruction. Preparation of the design requires good knowledge of the thermal properties of the insulation and other construction materials. Gypsum boards and gypsum-based filling materials are often used for modernization of interiors. The use of inappropriate materials can cause problems with deteriorated thermal insulation properties, thermal bridges, etc. For this reason, development is focused on the production and use of some new materials with better properties. This paper describes the method and the results of measurements focused on different construction materials based on gypsum, which are used mainly for the improvement of interiors of buildings. In this study, three different types of samples of gypsum materials were tested, one of which is a traditional gypsum board, the second one is a gypsum filler material and these samples are compared with the new light gypsum material developed by the Faculty of Environmental and Civil Engineering at the Latvia University of Life Sciences and Technologies in Jelgava. Experimental measurements of the test samples were carried out by the Faculty of Engineering at the Czech University of Life Sciences in Prague. The measurement principle is based on a dynamic unsteady method. The measurement consists of the analysis of the thermal response of the tested material to the heat flux pulses. The results of the measurement in real terms are compared with those specified by the manufacturer of building materials. All results of the research are processed by statistical evaluation.
\end{abstract}

Keywords: measurement, gypsum board, foam gypsum, thermal properties.

\section{Introduction}

Gypsum is one of the oldest building materials and has been used for millennia. Traditionally gypsum is used for small repairs of walls and plasters. As a building material, it meets all technical and user requirements even today. Gypsum is used for the production of plasterboard and gypsum fiberboards, internal plasters and self-leveling floor screeds.

Gypsum boards and gypsum-based filling materials are often used for modernization of interiors. The use of inappropriate materials can cause problems with deteriorated thermal insulation properties, thermal bridges, etc. For this reason, development is focused on the production and use of some new materials with better properties. Preparation of the design requires good knowledge of the thermal properties of the insulation and other construction materials.

The producers in the information catalogs of products usually describe the most common plasterboards and other produced materials and their properties [1]. Literature [2] presents the value of the thermal conductivity of the plates in the range $\lambda=0.19 \div 0.24 \mathrm{~W} \cdot \mathrm{m} \cdot \mathrm{K}^{-1}$. Important properties of this building material include thermal conductivity and fire resistance, so to the research and development of these properties attention is paid, e.g., in publications [3-6].

Properties of new materials with the addition of gypsum are studied, for example, by [7]. Thermal properties of gypsum and natural materials are researched in [8]. The study about thermal conductivity of plasterboard at high temperatures is presented in [9]. Modeling of the same issue is the topic of [10].

In this study, three different types of samples of gypsum materials were tested. First one is gypsum filler material made as a sample in the form of solid cast gypsum, the second one is a traditional gypsum board, the third one is a gypsum board with properties resistant against fire. These samples are compared with the new light gypsum materials (foam gypsum) developed by the Faculty of Environmental and Civil Engineering at the Latvia University of Life Sciences and Technologies in Jelgava.

\section{Materials and methods}

The results presented in this paper are based on the measurement of thermal conductivity by the portable instrument Isomet 2104 (Applied Precision, Ltd., Bratislava, Slovakia). The description of the instrument, measurement methods and evaluation of the results is described in the publication [11]. 
Air temperatures and relative humidity as well as material moisture were measured by the instruments described in [11].

The results of measurement were processed by Excel software and the results of thermal conductivity measurements were verified by statistical software Statistica 12 (ANOVA and TUKEY HSD Test). More details are given in [11].

\section{Tested materials}

Sample A is solid cast gypsum prepared by the Faculty of Engineering for comparison with other gypsum samples. The surface sensor was used for these sample measurements (Fig 1). Gypsum is recommended for constructional, heating and plumbing work. It can be used for fast fixation of dowels, pipes and cables in exterior and interior use. Freezing time is less than 11 minutes. Start of setting after 6 minutes. Bulk density of dry material is $900 \pm 200 \mathrm{~kg} \cdot \mathrm{m}^{-3}$. Distributor in the Czech Republic is Paints and varnishes Hostivař a. $s$.

Sample B is Knauf Wallboard [1], which is gypsum board with a face ideally suited to receive a plaster finish or for direct decoration. Thickness $12.5 \mathrm{~mm}$. The surface sensor was used for the sample measurements.

Sample C is Knauf Fire Panel [1], offers superior fire protection. Thickness $12.5 \mathrm{~mm}$. The surface sensor was used for the sample measurements.

Samples D, E, F and G are foam gypsum materials developed by the Faculty of Environmental and Civil Engineering at the Latvia University of Life Sciences and Technologies in Jelgava. These materials differ in density (Table 1) and preparation technology (D, F -one technology, E, G- another preparation technology).

The surface sensor was used for material D, F samples measurements (Fig. 1), but the needle sensor was used for samples E, G measurements (Fig. 2).

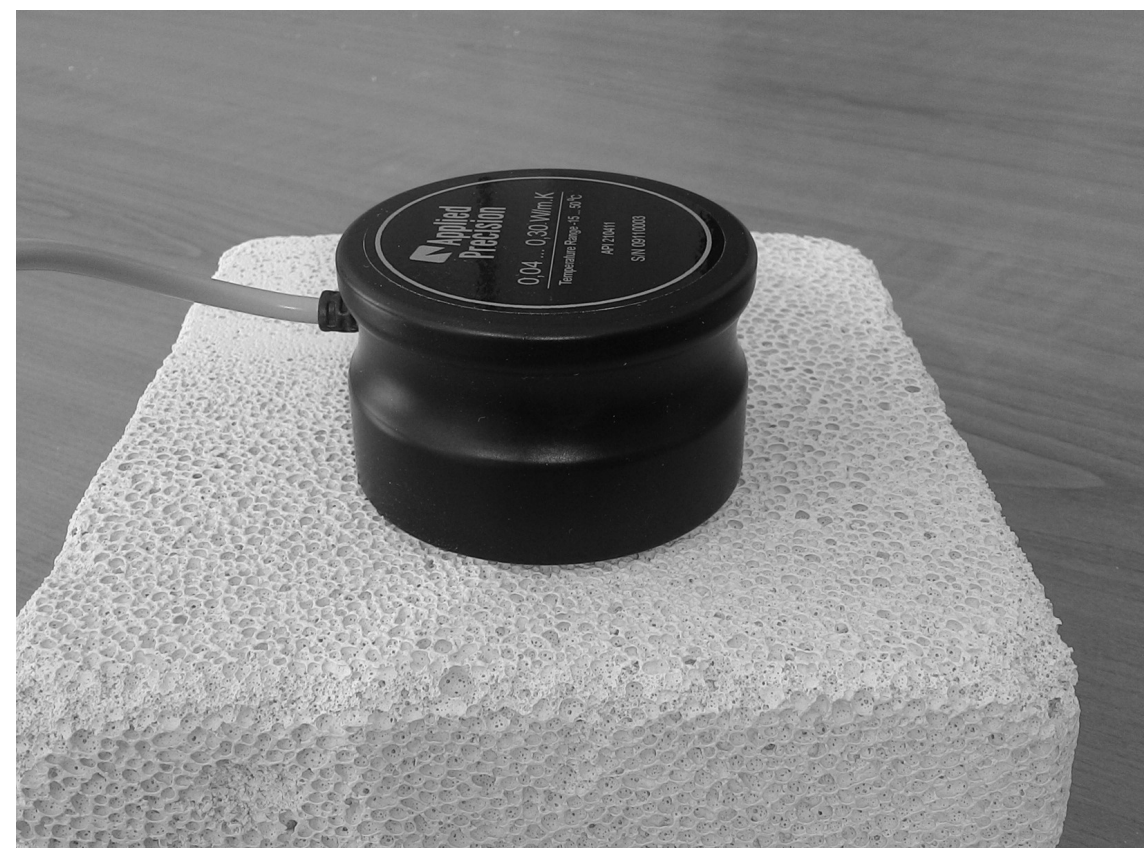

Fig. 1. Surface probe in material G measurement 


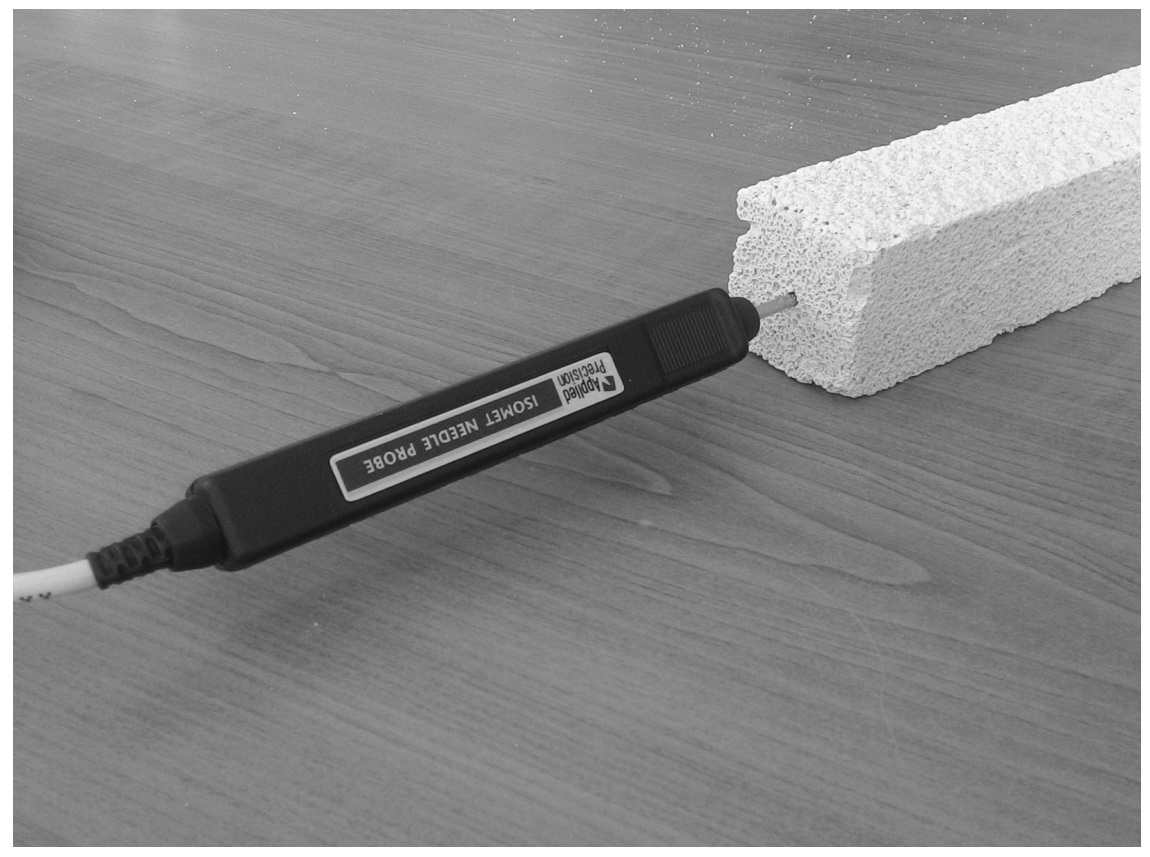

Fig. 2. Needle probe in material $\mathbf{F}$ measurement

\section{Results and discussion}

The results of measurement of thermal conductivity of all tested gypsum materials are presented in the Table 1.

There are included also the measurement conditions: density of the material sample $\rho_{m}$, average moisture of the material $w_{m}$, average temperature of the material sample at the beginning of the measurement $t_{m}$, average air temperature at the beginning of the measurement $\mathrm{t}_{\mathrm{e}}$ and the results of the measurement of thermal conductivity $\lambda_{m}$, which are compared with the value $\lambda$ declared by the manufacturer. The data are the mean values \pm SD.

Measurement of thermal conductivity of different gypsum materials

Table 1

\begin{tabular}{|c|c|c|c|c|c|c|c|c|}
\hline \multirow{2}{*}{ Parameter } & \multirow{2}{*}{ Units } & \multicolumn{7}{|c|}{ Measurement samples } \\
\cline { 3 - 9 } & & A & B & C & D & E & F & G \\
\hline aver. val. $\rho_{m}$ & $\mathrm{~kg} \cdot \mathrm{m}^{-3}$ & 1430 & 740 & 860 & 260 & 260 & 360 & 360 \\
\hline aver. val. $w_{m}$ & $\%$ & 4.1 & 2.2 & 2.8 & 0.6 & 0.6 & 1 & 1 \\
\hline aver. val. $t_{m}$ & ${ }^{\circ} \mathrm{C}$ & 23.8 & 24.1 & 23.9 & 29.3 & 26.6 & 29.1 & 26.4 \\
\hline aver. val. $t_{e}$ & ${ }^{\circ} \mathrm{C}$ & 23.5 & 23.9 & 23.7 & 28.5 & 26.4 & 28.6 & 26.1 \\
\hline$\lambda_{m} \pm \mathrm{SD}$ & \multirow{2}{*}{$\mathrm{W} \cdot \mathrm{m}^{-1} \cdot \mathrm{K}^{-1}$} & $0.482 \pm$ & $0.216 \pm$ & $0.250 \pm$ & $0.080 \pm$ & $0.076 \pm$ & $0.102 \pm$ & $0.096 \pm$ \\
& & $0.010^{\mathrm{a}}$ & $0.002^{\mathrm{b}}$ & $0.007^{\mathrm{c}}$ & $0.002^{\mathrm{d}}$ & $0.003^{\mathrm{d}}$ & $0.002^{\mathrm{e}}$ & $0.002^{\mathrm{e}}$ \\
\hline
\end{tabular}

The data are the mean values \pm SD. Different letters (a, b, c, d, e) in the subscript are the sign of high significant differences (ANOVA; Tukey HSD Test; $p \leq 0.05$ ).

\section{Conclusions}

1. The traditional untreated gypsum in the form of solid cast block has the greatest thermal conductivity and density. The thermal conductivity corresponds to modern brick masonry systems. When repairing porous concrete with this material, the surface temperature of the masonry may be reduced. When repairing masonry made of solid clay bricks, there is not this danger.

2. The thermal conductivity of the solid cast gypsum is approximately twice bigger than the industrial products as wallboard or fire-panel. The fire-panel has higher thermal conductivity than normal wallboard. 
3. The foam gypsum material developed by the Faculty of Environmental and Civil Engineering at the Latvia University of Life Sciences and Technologies in Jelgava has significantly lower thermal conductivity than industrial products.

4. Combining gypsum material with air-filled pores greatly reduces the thermal conductivity.

5. Tests of thermal conductivity have shown that there is no statistically significant difference between the results of the surface and needle probe measurements. From a practical point of view, however, it is simpler and more convenient to use a surface probe for these measurements.

\section{References}

[1] Knauf - Product data sheets [online] [1.03.2018]. Available at: http:// www.knauf.co.uk/productdata-sheets

[2] Wang Y., Burgess I., Wald F., Gillie M. Performance-Based Fire Engineering of Structures. Boca Raton: CRC Press, 2013. 369 p.

[3] Aboltins A., Kalis H., Kangro I. On mathematical modelling of heat and moisture distribution in the drying process for porous two layered gypsum board products. Proceedings of 16th International Scientific Conference on "Engineering for Rural Development", May 24-26, 2017, Jelgava, Latvia, pp. 134-141.

[4] Aboltins A., Kalis H., Pulkis K., Skujans J., Kangro I. Mathematical modelling of heat of heat transfer problems for two layered gypsum board products exposed to fire. Proceedings of 16th International Scientific Conference on "Engineering for Rural Development", May 24-26, 2017, Jelgava, Latvia, pp. 1369-1376.

[5] Ariyanayagam A. D., Mahen Mahendran M. Residual capacity of fire exposed light gauge steel frame walls. Thin-Walled Structures, vol. 124, 2018, pp. 107-120.

[6] Yanqiu Chen Y., Naveen Punati N., Ray S. S., Yang L., Prasad K. Thermal failure time of nonloadbearing gypsum board assemblies in standard furnace tests. Applied Thermal Engineering, vol. 127, 2017, pp. 1285-1292.

[7] Bicer A., Kar F. Thermal and mechanical properties of gypsum plaster mixed with expanded polystyrene and tragacanth. Thermal Science and Engineering Progress, vol. 1, 2017, pp. 59-65.

[8] Musa M. N., Aziz M. F. A. Thermal Conductivity for Mixture of Rice Husk Fiber and Gypsum. Applied Mechanics and Materials, vol. 819, 2016, pp. 69-73.

[9] Rahmanian I., Wang Y. Thermal Conductivity of Gypsum at High Temperatures. Acta Polytechnica, vol. 49, 2019, pp. 16-20.

[10] Korte A. C. J., Brouwers H. J. H. Calculation of thermal conductivity of gypsum plasterboards at ambient and elevated temperature. Fire and Materials, vol. 34, 2010, pp. 55-75.

[11] Neuberger, P. Kic, P. Thermal conductivity of natural materials used for thermal insulation. Proceedings of 16th International Scientific Conference on "Engineering for Rural Development", May 24-26, 2017, Jelgava, Latvia, pp. 420-424. 